\title{
Real-time tracheal ultrasonography for confirming endotracheal tube placement
}

\author{
Ahmed E. Kabil ${ }^{a}$, Ahmed M. Ewis ${ }^{a}$, Ahmed M. Al-Ashkar ${ }^{b}$, \\ Mohamed A.A. Abdelatif ${ }^{\mathrm{c}}$, Mohamed O. Nour ${ }^{\mathrm{d}, \mathrm{e}}$
}

\begin{abstract}
Objective To evaluate the accuracy of tracheal ultrasonography for confirming the endotracheal tube placement during patients' intubation.
\end{abstract}

Patients and methods The current study was a prospective, randomized study performed at the ICU of Al-Hussein Hospital, Cairo. Intubated for respiratory failure, cardiac arrest or other medical causes were included in the current study. Real-time tracheal ultrasonography was conducted during intubation with the ultrasound probe placed transversely over the trachea above the suprasternal notch for confirming the tube position, either tracheal or esophageal. The standard method for confirming endotracheal tube placement include clinical evaluation and rapid bronchoscopic confirmation. The main outcomes were the degree of accuracy and timeliness of tracheal ultrasound in confirming endotracheal tube placement.

Results Forty patients eligible for endotracheal intubation were randomized in the current study and only four (10\%) patients had confirmed esophageal intubations. Our results concluded that tracheal ultrasound had a diagnostic accuracy of $97.5 \%$ in the detection of endotracheal tube site. The sensitivity was $97.2 \%$, while the specificity was $100 \%$.

\section{Introduction}

The process of confirmation of endotracheal tube site may be challenging for the majority of ICU physicians $[1,2]$.

Sometimes, it may be very difficult to see the glottis, especially with difficult intubation [3]. Physical examination, pulse oximetry, and chest radiography are not reliable as definite methods to detect the endotracheal tube position [4]. Esophageal detection device is unavailable in many places and can be misinterpreted [5]. Capnography is advised as the more trustable tool for the confirmation of endotracheal tube position [6]. On the other hand, capnography may be not widely available and it has many limitations $[7,8]$. At least six breaths are required for the stomach to be completely cleared of $\mathrm{CO}_{2}[9]$. Fiberoptic bronchoscopy is expensive and invasive [10].

Ultrasound is a simple, real-time, and less invasive diagnostic method that is commonly used in the ICU for many other causes [11].

The aim of this study was to evaluate the diagnostic performance and timeliness of real-time tracheal sonography in confirming endotracheal tube position during patient's intubation in the ICU.
Tracheal ultrasound had a positive predictive value of $100 \%$, while the negative predictive value was $80 \%$. The total operating time of ultrasonography was significantly lower than that of bronchoscopy.

Conclusion Real-time ultrasound of the trachea is an accurate, feasible, and fast method in confirming endotracheal tube placement.

Egypt J Bronchol 2018 12:323-328

(C) 2018 Egyptian Journal of Bronchology

Egyptian Journal of Bronchology 2018 12:323-328

Keywords: endotracheal intubation, esophageal intubation, tracheal ultrasonography

Departments of, a Chest Diseases, ${ }^{\mathrm{b}}$ Internal Medicine, ${ }^{\mathrm{c}}$ Radiology, Al-Azhar University, Cairo, ${ }^{d}$ Department of Public Health and Community Medicine, Faculty of Medicine, Al-Azhar University, Damietta, Egypt, ${ }^{\mathrm{e}}$ Faculty of Public Health and Health Informatics, Umm Al-Qura University, Makkah, Saudi Arabia

Correspondence to Ahmed M. Ewis, MD, Chest Department, Faculty of Medicine, Al-Azhar University, Cairo, Egypt. Tel: +201007046567; e-mail: ahmedew33@gmail.com

Received 9 September 2017 Accepted 21 January 2018

\section{Patients and methods}

The current study was a prospective, observational study, conducted at the respiratory and medical ICUs, Al-Hussein University Hospital, over the period from June 2015 to November 2016. A written consent was taken from the relatives of each patient.

\section{Inclusion criteria}

The study included patients who underwent endotracheal intubation as a result of respiratory failure, cardiac arrest, or other medical causes at the respiratory or medical ICUs. The patients were included during the times when at least two of the investigators were on duty.

\section{Exclusion criteria}

The exclusion criteria were: (a) neck trauma, (b) neck malignancy, (c) neck surgery or tracheostomy, (d) age under 18 years (we conducted this study in the adult respiratory ICU).

This is an open access journal, and articles are distributed under the terms of the Creative Commons Attribution-NonCommercial-ShareAlike 4.0 License, which allows others to remix, tweak, and build upon the work non-commercially, as long as appropriate credit is given and the new creations are licensed under the identical terms. 
For patients with esophageal intubation, the first intubation was only included in the study (the second intubation was endotracheal).

Patients intubation was done by senior ICU residents, under supervision of the attending physicians on duty. Tracheal ultrasound was performed concurrently with intubation by one of the contributing physicians (other than a radiologist), who had completed the airway ultrasound training course. All ultrasound images were saved and revised by a radiologist later. After completing the intubation confirming endotracheal tube position was performed using a rapid fiberoptic bronchoscopy examination of the tube done by another attending chest physician.

A convex ultrasound probe was used for examination. The probe was placed transversely just above the suprasternal notch. The trachea can be detected easily by a hyperechoic air-mucosa (A-M) interface with the radiating artifact shadow posteriorly (comet-tail artifact). During intubation, the endotracheal tube site was immediately detected by ultrasound. The place of intubation was determined by ultrsonography as (a) in the trachea if only a single A-M interface with comet-tail artifact and posterior shadowing was detected or (b) in the esophagus if double A-M interfaces with comet-tail artifacts and posterior shadowing were seen, called a 'double tract sign'. The operating time required for ultrasound confirmation was recorded. The ultrasound operating time was defined as the period between finishing endotracheal tube placement and completing ultrasound scan to obtain the final decision [12].

The primary outcome was the comparison between tracheal ultrasonography and fiberoptic bronchoscopy for confirming endotracheal tube placement. Fiberoptic bronchoscopy was used as the criterion standard as regards confirming tracheal intubation. The secondary outcome was the total time consumed during tracheal ultrasound for confirming the endotracheal tube position (Figs. 1 and 2).

\section{Ethical consideration}

The study was approved by the Ethics Committee of Faculty of Medicine, Al-Azhar University and a written consent was taken from the first-degree relatives of each patient.

\section{Statistical analysis}

Statistical analysis was done using the SPSS computer package, version 19.0 (SPSS Inc., Chicago, Illinois, USA). For descriptive statistics, the mean \pm SD was used for quantitative variables while the number and percentage were used for qualitative variables. In univariate analyses, the qualitative variables were compared by $\chi^{2}$-test or Fischer's exact test when appropriate and the quantitative variables were compared by independent samples $t$-test. Sensitivity, specificity, accuracy, and positive and negative predictive values were calculated for the determination of tube placement. The statistical methods were verified, assuming a significant level of $P$ value of less than 0.05 and a highly significant level of $P$ value of less than 0.001 .

\section{Results}

Forty patients were included in this study. The history and clinical characteristics of the patients were achieved from the relatives or from the existing hospital files and investigations. Their demographics and clinical features are shown in Table 1.

\section{Figure 1}

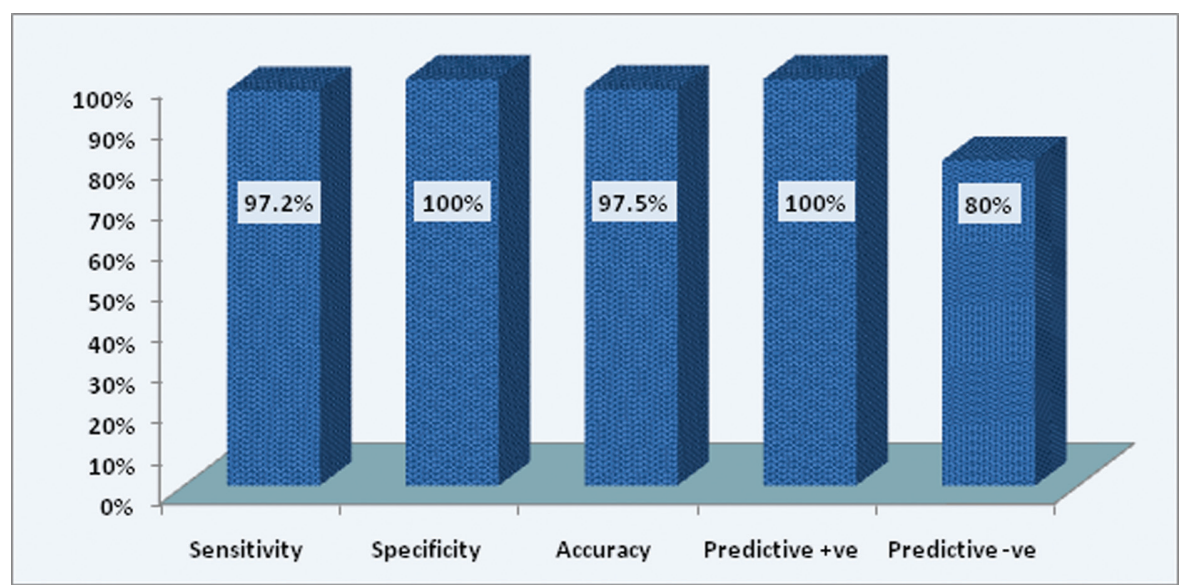


Figure 2

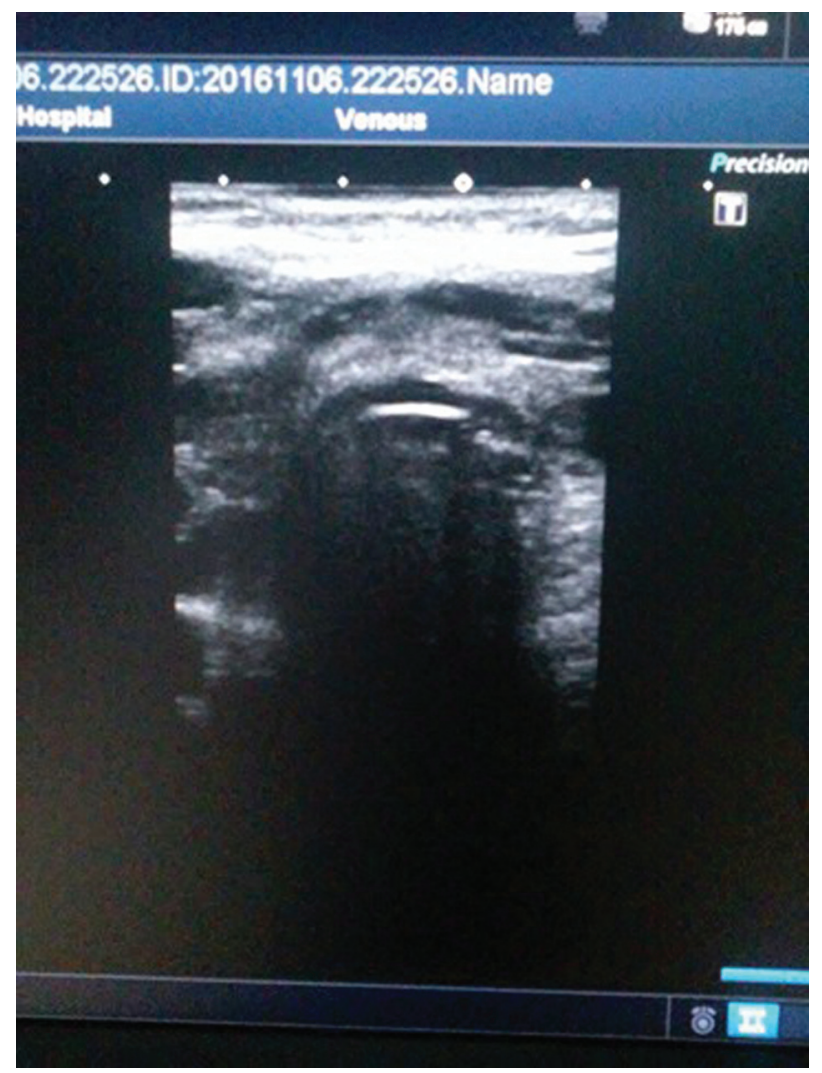

Ultrasonic image of correct endotracheal intubation.

Among the studied sample, only four patients had esophageal intubation and 36 patients had tracheal intubation after clinical and fiberoptic bronchoscopy confirmation of the tube position. The demographics and clinical features of both the groups are shown in Table 2.

The findings of tracheal ultrasonography assessment of tube position are shown in Table 3. Ultrasound detected tracheal intubation in 35 patients (97.22\% of all patients with true tracheal intubation). Only one patient with tracheal intubation was detected by ultrasound as esophageal (2.78\%). All patients with esophageal intubation $(n=4)$ were correctly detected by ultrasound as esophageal intubation.

The diagnostic accuracy of ultrasonographical examination for confirming endotracheal tube placement was $97.5 \%$. The sensitivity and specificity were 97.2 and $100 \%$, respectively. The positive predictive value and the negative predictive value were 100 and $80 \%$, respectively.

The time spent in the procedure of tracheal ultrasonography is recorded in Table 4, with significant shorter duration than the duration of fiberoptic bronchoscopy.
Table 1 General characteristics and airway data of the studied sample

\begin{tabular}{lc}
\hline Characteristics & Mean \pm SD/n $(\%)$ \\
\hline Age & $55.75 \pm 10.01$ \\
Sex & \\
Male & $26(65.0)$ \\
Female & $14(35.0)$ \\
Diagnosis & \\
COPD exacerbation & $20(50.0)$ \\
OHS & $10(25.0)$ \\
Overlap & $4(10.0)$ \\
ARDS & $6(15.0)$ \\
BMI & $34.3 \pm 7.1$ \\
Mallampati class & \\
Class 1 & $10(25.0)$ \\
Class 2 & $10(25.0)$ \\
Class 3 & $20(50.0)$ \\
Thyromental distance & $6.74 \pm 0.6$ \\
Type of intubation & \\
Elective & $10(25.0)$ \\
Urgent & $30(75.0)$ \\
SO $\%$ before & $83.45 \pm 5.81$ \\
SO $\%$ after & $90.4 \pm 6.42$ \\
In the trachea & \\
In the esophagus & $36(90.0)$ \\
\hline ARDS acute respiratory & $4(10.0)$ \\
\hline
\end{tabular}

ARDS, acute respiratory distress syndrome; COPD, chronic obstructive pulmonary disease; OHS, obesity hypoventilation syndrome.

\section{Discussion}

The aim of this study was identification of the accuracy and timeliness of tracheal ultrasonography to confirm the endotracheal tube positioning in respiratory and medical ICU patients. As evidenced by 2010 advanced cardiac life support (ACLS) guidelines, the position of endotracheal tube need to be confirmed clinically and also by using confirmative tool after intubation to avoid the catastrophic effects of esophageal intubation [12]. However, there are some limitations for each confirmation technique. Even when performed by experienced physicians, there is still issue of unreliability as regards the clinical assessment of endotracheal tube position [7]. The most common clinical methods for confirming endotracheal intubation are auscultation of the chest by a stethoscope and detection of chest wall movement and expansion. However, these methods may interfere with chest compressions during cardiopulmonary resuscitation. Quantitative waveform capnography has been considered as the gold standard to confirm endotracheal intubation. Nevertheless, waveform capnography requires good ventilation as well as adequate pulmonary vascular flow to give reliable results. It may give false-positive (e.g. nonfasting patient with gastric $\mathrm{CO}_{2}$ production) [13], and false-negative results (e.g. low pulmonary flow, use 
Table 2 General characteristics and airway data of both groups

\begin{tabular}{|c|c|c|c|c|}
\hline Characteristic & Tracheal intubation $(N=36)$ & Esophageal intubation $(N=4)$ & $t /$ FET & $P$-value \\
\hline Age & $55.44 \pm 10.29$ & $58.5 \pm 7.51$ & 0.57 & 0.569 \\
\hline \multicolumn{5}{|l|}{ Sex } \\
\hline Male & $24(66.7)$ & $2(50.0)$ & \multirow[t]{2}{*}{0.60} & \multirow[t]{2}{*}{0.438} \\
\hline Female & $12(33.3)$ & $2(50.0)$ & & \\
\hline \multicolumn{5}{|l|}{ Diagnosis } \\
\hline COPD exacerbation & $18(50.0)$ & $2(50.0)$ & \multirow[t]{4}{*}{8.89} & \multirow[t]{4}{*}{0.031} \\
\hline OHS & $10(27.8)$ & $0(0.0)$ & & \\
\hline Overlap & $2(5.6)$ & $2(50.0)$ & & \\
\hline ARDS & $6(16.7)$ & $0(0.0)$ & & \\
\hline BMI & $33.44 \pm 6.95$ & $42.0 \pm 2.31$ & 2.42 & 0.020 \\
\hline \multicolumn{5}{|l|}{ Mallampati class } \\
\hline Class 1 & $10(27.8)$ & $0(0.0)$ & \multirow[t]{3}{*}{4.44} & \multirow[t]{3}{*}{0.108} \\
\hline Class 2 & $10(27.8)$ & $0(0.0)$ & & \\
\hline Class 3 & $16(44.4)$ & $4(100.0)$ & & \\
\hline Thyromental distance & $6.81 \pm 0.59$ & $6.1 \pm 0.12$ & 2.36 & 0.023 \\
\hline \multicolumn{5}{|l|}{ Type of intubation } \\
\hline Elective & $10(27.8)$ & $0(0.0)$ & \multirow[t]{2}{*}{0.56} & \multirow[t]{2}{*}{0.300} \\
\hline Urgent & $26(72.2)$ & $4(100.0)$ & & \\
\hline $\mathrm{SO}_{2} \%$ before & $83.94 \pm 5.77$ & $79.0 \pm 4.62$ & 1.65 & 0.107 \\
\hline $\mathrm{SO}_{2} \%$ after & $91.94 \pm 4.08$ & $76.5 \pm 7.51$ & 6.59 & $<0.001$ \\
\hline
\end{tabular}

ARDS, acute respiratory distress syndrome; COPD, chronic obstructive pulmonary disease; FET, Fischer's exact test; OHS, obesity hypoventilation syndrome.

Table 3 Ultrasonographic detection of tracheal and esophageal intubation

\begin{tabular}{lcccc}
\hline & $\begin{array}{c}\text { Tracheal } \\
\text { intubation } \\
(N=36) \\
{[n(\%)]}\end{array}$ & $\begin{array}{c}\text { Esophageal } \\
\text { intubation } \\
(N=4)\end{array}$ & $\begin{array}{c}\text { Fischer's } \\
\text { exact test }\end{array}$ & $P$-value \\
& {$[n(\%)]$} & & \\
\hline $\begin{array}{l}\text { Ultrasound } \\
\text { tracheal }\end{array}$ & $35(97.22)$ & $0(0.0)$ & 31.1 & $<0.001$ \\
$\begin{array}{l}\text { Ultrasound } \\
\text { esophageal }\end{array}$ & $1(2.78)$ & $4(100)$ & & \\
\hline
\end{tabular}

of epinephrine drugs, technical error, or airway obstruction), during cardiopulmonary resuscitation $[7,8]$. Unfortunately, quantitative waveform capnography is not available and is hardly applicable in many places.

In recent surveys of the National Emergency Airway Registry Series, despite the availability of colorimetric end-tidal $\mathrm{CO}_{2}$ probes were in $77 \%$ of physicians at their hospitals, only about one-third of them used continuous quantitative capnogram [14]. Fiberoptic bronchoscopy can be used to confirm the correct position of the tube with highly successful, more reliable results. Observation of the rings and bifurcation of the trachea is achieved easily by the bronchoscopist. It may be difficult to see due to misting, secretions, and hemorrhage. The bronchoscope is relatively expensive with liability to be broken. Also, the use of bronchoscopy is not widely available for routine confirmation of the tube position [15]. Thus, it is advisable to use other confirmatory techniques wherein
Table 4 Time required for confirmation of endotracheal tube position (s)

\begin{tabular}{lcccc}
\hline & Mean & SD & $t$ & $P$-value \\
\hline By ultrasound & 10 & 9.38 & 2.01 & 0.048 \\
By bronchoscopy & 15 & 12.67 & & \\
\hline
\end{tabular}

$t$, independent samples $t$-test.

there is no interruption with compression of the thorax during cardio-pulmonary resuscitation (CPR).

Ultrasound has become widely used and easy with high diagnostic yield in many critical care areas and chest departments. The 2010 European Resuscitation Council Guidelines, in the scope of the International Liaison Committee on Resuscitation Consensus on Science and Treatment Recommendations, recognized the value of ultrasonography as an adjuvant for the diagnosis and treatment of the possible reversible causes of cardiac arrest $[16,17]$.

The use of ultrasonography for confirming endotracheal tube placement is advisable due to many causes as it is portable, can be repeated many times, cost-effective, noninvasive, and a painless method.

For confirming endotracheal tube placement, three windows have been used: the first window is tracheal (direct), the second is intercostals (indirect), and the third is subxiphoid, or diaphragmatic (indirect). The indirect ultrasonographic methods use pleural sliding and diaphragmatic movement to 
assess tracheal intubation $[18,19]$; these techniques may interfere with chest compression during $\mathrm{CPR}$ and mechanical ventilation of the patient is also required. These techniques may be affected by underlying lung diseases, for example, pneumothorax.

Direct tracheal ultrasound shows the anatomy of the larynx and trachea independent of patient physiology, and it is not affected like capnography by other factors such as low pulmonary flow. Also, this technique of tracheal ultrasound can detect undesired esophageal intubation even before mechanical ventilation of the patient, and this in turn prevents further forced ventilation which introduces a large air volume to the stomach and with subsequent undesirable associated complications.

It is well known that ultrasonography is a technique which is dependent on operator skills and experience; on the other hand, it is relatively easy to learn and to interpret tracheal ultrasound images confirming the intubation. Rosenstein et al. [20] have shown that physicians with low experience are more reliably and easily interpreting transverse views of tracheal ultrasound to confirm endotracheal tube position.

In this study, we used a curved probe which is more available and common to use through the suprasternal notch window. This window was used as it is more accurate in visualizing the trachea and the esophagus and hence the position of the endotracheal tube [21]. Also, we used real-time dynamic assessment during the process of intubation which may appear more accurate and more rapid. In this technique, if the endotracheal tube has been introduced falsely into the esophagus, there was appearance of another hyperechoic A-M interface artifacts with posterolateral shadowing to the trachea [12].

In the current study, real-time tracheal ultrasonography has a high diagnostic accuracy with high sensitivity and specificity for confirming endotracheal tube position during intubation of the patients in respiratory ICU.

These results are in agreement with two prospective studies done by Werner et al. [21] and Milling et al. [22]. They found that tracheal ultrasound achieved up to $100 \%$ sensitivity and specificity under ideal settings in the procedure room.

It is also coincides with Karacabey et al. [23], who showed that real-time tracheal ultrasound has high sensitivity and specificity for confirming endotracheal tube position and with faster results than capnography.
However, they added ultrasonographic lung sliding sign to the technique to avoid one-lung ventilation with bronchial intubation.

A recent systematic review and meta-analysis which was done by Chou et al. [24] concluded the high efficacy of ultrasonography in the diagnosis of esophageal intubation. Moreover, it can be used as adjunct evidence with high sensitivity and specificity in the assessment of the airway, especially in many units where the capnometry is unavailable and if available may be unreliable.

Our results also had demonstrated that tracheal ultrasound is less time consuming than bronchoscopy in confirming the tube position. This is an important issue in the airway management procedure. In agreement with our results, Karacabey et al. [23] reported that ultrasonography took significantly less time than capnography in confirming endotracheal tube placement.

However, there are some limitations to our study. First, it was a single-center study with a relatively low number of patients, especially those with esophageal intubation. Further multicenters studies with a larger sample of subjects are recommended. The unavailability of capnography in our study appears as another limitation to be considered in other studies.

\section{Conclusion}

Ultrasonography is a good, rapid, and feasible method for confirming endotracheal tube placement in RICU with a high degree of sensitivity and specificity and more advantages than other methods.

\section{Acknowledgements}

Ahmed E. Kabil, and Ahmed M. Ewis carried out fiberoptic bronchoscopy and tracheal ultrasound. Ahmed M. Al-Ashkar carried out tracheal ultrasound. Mohamed A.A. Abdelatif carried out tracheal ultrasound images. Mohamed O. Nour carried out statistics.

\section{Financial support and sponsorship} Nil.

\section{Conflicts of interest}

There are no conflicts of interest.

\section{References}

1 1Schwartz DE, Matthay MA, Cohen NH. Death and other complications of emergency airway management in critically ill adults. A prospective 
investigation of 297 tracheal intubations. Anesthesiology 1995; 82: 367-76.2.

2 2Mort TC. Unplanned tracheal extubation outside the operating room: a quality improvement audit of hemodynamic and tracheal airway complications associated with emergency tracheal reintubation. Anesth Analg 1998; 86:1171-6.3.

3 Salem MR, Baraka A. Confirmation of tracheal intubation. In: Benumof JL, editor. Airway management: principles and practice. New York, NY: CV Mosby Co; 1996. pp. 531-560.

4 ACEP Board of Directors. Verification of endotracheal tube placement. Ann Emerg Med 2009; 54:141-142.

5 Ma G, Davis DP, Schmitt J. The sensitivity and specificity of transcricothyroid ultrasonography to confirm endotracheal tube placement in a cadaver model. J Emerg Med 2007; 32:405-407.

6 ECC Committee, Subcommittees and Task Forces of the American Heart Association. American Heart Association Guidelines for cardiopulmonary resuscitation and emergency cardiovascular care. Part 8.1: Adjuncts for airway control and ventilation. Circulation 2010; 112:S729-S735.

7 Takeda T, Tanigawa K, Tanaka H, Hayashi Y, Goto E, Tanaka K. The assessment of three methods to verify tracheal tube placement in the emergency setting. Resuscitation 2003; 56:153-157.

8 Levine RL, Wayne MA, Miller CC. End-tidal carbon dioxide and outcome of out-of-hospital cardiac arrest. N Engl J Med 1997; 337:301-306.

9 Clyburn P, Rosen M. Accidentaloesophageal intubation. Br J Anaesth 1994; 73:55-63.

10 Koppel JN. Learning fiberoptic-guided endotracheal intubation. Mt Sinai J Med 1995; 62:41-46.

11 Abbasi S, Farsi D, Zare MA, Hajimohammadi M. Direct ultrasound methods: a confirmatory technique for proper endotrachealintubation in the emergency department. Eur J Emerg Med 2015; 22:10-16.

12 Chou HC, Tseng WP, Wang CH. Tracheal rapid ultrasound exam (T.R.U.E.) for confirming endotracheal tube placement during emergency intubation. Resuscitation 2011; 82:1279-1284.

13 Sayah AJ, Peacock WF, Overton DT. End-tidal $\mathrm{CO}_{2}$ measurement in the detection of esophageal intubation during cardiac arrest. Ann Emerg Med 1990; 19:857-860.
14 Deiorio NM. Continuous end-tidal carbon dioxide monitoring for confirmation of endotracheal tube placement is neither widely available nor consistently applied by emergency physicians. Emerg Med J 2005; 22:490-493.

15 Muslu B, Sert H, Kaya A, Demircioglu RI, Gözdemir M, Usta B, et al. Use of sonography for rapid identification of esophageal and tracheal intubations in adult patients. $J$ Ultrasound Med 2011; 30: 671-676.

16 Deakin CD, Nolan JP, Soar J. European resuscitation council guidelines for resuscitation2010. Section 4. Adult advanced life support. Resuscitation 2010;81:1305-1352.

17 Deakin CD, Morrison LJ, Morley PT. International consensus on cardiopulmonary resuscitation and emergency cardiovascular care science with treatment recommendations. Part 8: advanced life support. Resuscitation 2010;81:e93-e174.

18 Hsieh KS, Lee CL, Lin CC. Secondary confirmation of endotracheal tube position by ultrasound image. Crit Care Med 2004; 32(Suppl): S374-S377.

19 Weaver B, Lyon M, Blaivas M. Confirmation of endotracheal tube placement after intubation using the ultrasound sliding lung sign. Acad Emerg Med 2006; 13:239-244.

20 Rosenstein AL, Jones RA, Werner SL, Meurer WJ. Ultrasound as a tool to confirm tracheal intubation [abstract]. Acad Emerg Med 2004; 11 (Suppl):5.

21 Werner SL, Smith CE, Goldstein JR. Pilot study to evaluate the accuracy of ultrasonography in confirming endotracheal tube placement. Ann Emerg Med 2007; 49:75-80.

22 Milling TJ. Transtracheal 2-D ultrasound for identification of esophageal intubation. J Emerg Med 2007; 32:409-414.

23 Karacabey S, Sanri E, Gencer EG, Guneysel O. Tracheal ultrasonography and ultrasonographic lung sliding for confirming endotracheal tube placement: speed and reliability. Am J Emerg Med 2016; 34:953-956.

24 Chou EH, Dickman E, Tsou PY, Tessaro M, Tsai YM. Ultrasonography for confirmation of endotracheal tube placement: a systematic review and meta-analysis. Resuscitation 2015; 90:97-103. 